\title{
The ISPOL drift experiment
}

\author{
H. H. Hellmer ${ }^{a, *}$ M. Schröder ${ }^{a}$, C. Haas ${ }^{a, b}$, G.S. Dieckmann ${ }^{a}$, \\ M. Spindler ${ }^{c}$ \\ ${ }^{a}$ Alfred Wegener Institute for Polar and Marine Research, Am Handelshafen 12, \\ D-27570 Bremerhaven, Germany \\ ${ }^{b}$ now at Department of Earth $\mathcal{E}$ Atmospheric Sciences at University of Alberta, \\ Edmonton T6G 2E3, Canada \\ ${ }^{c}$ Institute for Polar Ecology, Wischhofstraße 1-3, \\ D-24148 Kiel, Germany
}

\begin{abstract}
The "Ice Station POLarstern" (ISPOL) drift experiment was an interdisciplinary study within the perennial sea ice of the western Weddell Sea which brought together scientists from eleven countries. The primary goal was the monitoring of physical and biogeochemical interactions between atmosphere, ice, and ocean at the transition from austral winter to summer. Special emphasis was set on the processes controlling sea-ice melting and the onset of phytoplankton bloom. The ISPOL observations complement the study of the seasonal sea ice-ocean cycle in the western Weddell Sea, initiated by the summer to winter drift of Ice Station Weddell-1 (ISW-1) in 1992. This volume contains a collection of papers that range from the atmosphere to the deep ocean, from micro to makro scales, from physics to biology with their interactions investigated during the 36 days of the ISPOL experiment.
\end{abstract}

Key words: Weddell Sea, sea ice, biogeochemistry, marine biology, ocean fluxes 


\section{Background}

Intense sea-ice formation on the southern continental shelf, convergence of sea ice of different age and origin towards the west, and an upper ocean structure which limits the oceanic heat flux to a few Watts per square meter, all support a perennial sea-ice cover in the western Weddell Sea, the largest in the Southern Ocean. Few hydrographic observations in this area and further downstream, off the tip of the Antarctic Peninsula, indicate that the western Weddell Sea hosts significant though intermittend sources for deep and bottom water (Schröder et al., 2002), which escape from the Weddell Sea through passages in the South Scotia Ridge (Naveira Garabato et al., 2002) to ventilate as Antarctic Bottom Water the global ocean abyss. As the Antarctic sea ice starts melting it behaves differently from its Arctic cousin. Missing melt ponds and the development of gap-like porous internal layers with extremely high amounts of algal standing stocks have large implications for primary productivity, biogeochemical cycles, and the sequestration of anthropogenic greenhouse gases (Haas et al., 2001; Thomas et al., 2001). In winter, the ice pack provides the habitat for a rich algal community which is food for the Antarctic krill (Euphausia superba). For ice concentrations above $85 \%$ sea-ice movement controls the drift of icebergs of all sizes, thus determing the distribution of glacial meltwater in the upper Weddell Sea water column (Schodlok et al., 2006). Although the processes dominant during the transition from summer to winter were revealed at Ice Station Weddell-1 (Andreas and Claffy, 1995; Fritsen et al., 1994; Lytle and Ackley, 1996), the internal structure, processes, and forces of an ice pack moving into warmer season, its interaction with the

* Corresponding author

Email address: Hartmut.Hellmer@awi.de (H. H. Hellmer $\left.{ }^{a}\right)$. 
atmosphere and ocean, and the consequences for biology within and underneath still needed a comprehensive investigation. Therefore, the Ice Station POLarstern (ISPOL) observations at the onset of summer complete the investigation of the seasonal sea ice/ocean cycle, commenced by ISW-1 (Gordon, 1993).

\section{The ISPOL experiment}

Heavy sea ice in the central Weddell Sea prevented a smooth transit to the final destination in the southwestern Weddell Sea pack (Fig. 1a) but allowed for 12 on-transit stations. By means of ice coring sea-ice physical, biological, and biogeochemical parameters were sampled to observe spatial changes while passing from a region of predominantly first-year ice in the central Weddell Sea to the second-year ice regime of the ISPOL study area. The measurements were supplemented by snow sampling and airborne thickness surveys. On 27 November, 2004 the German research icebreaker RV Polarstern reached the southernmost position at $68.2^{\circ} \mathrm{S}$ (Fig. 1a), anchored to an initially $10 \mathrm{~km} \times 10 \mathrm{~km}$ sized floe. The latter was composed of 2-m thick second-year ice, interspersed by firstyear ice with modal thicknesses of $0.9 \mathrm{~m}$ and $1.8 \mathrm{~m}$ (Fig. 2c). ISPOL drifted over smooth topography primarily above the 1500-m isobath with a mean distance to the continental shelf break ( $\approx 500 \mathrm{~m}$ water depth) of $30 \mathrm{~km}$ (Fig. 1b). Towards the end of the drift water depth decreased to less than $1000 \mathrm{~m}$ as ISPOL encountered a so far uncharted eastward extension of the continental shelf. The net south-north displacement of $98 \mathrm{~km}$ between the start and the end at $66.9^{\circ} \mathrm{S}$ corresponds to an average northward drift of $<3 \mathrm{~km} /$ day. This is less than the $\sim 7 \mathrm{~km} /$ day observed in other seasons (Gordon, 1993), thus 
reflecting the dominance of northerly to easterly wind during the experiment (Dieckmann et al., 2007). Nevertheless, ISPOL covered a total distance of $290 \mathrm{~km}$ due to various loops in the ice-floe trajectory (Fig. 1b). These loops seem common since ISW-1 and tagged ice floes and icebergs followed similar deflections during their northerly course in the western Weddell Sea.

For 36 days RVPolarstern served an interdisciplinary scientific team from 11 countries (Australia, Belgium, Brasil, Canada, Finland, Germany, Greece, Netherlands, Russia, United Kingdom, and U.S.A.) as accommodation and laboratory as well as platform for field and water column studies. On the initial floe, nine sampling sites were numbered clockwise first on arrival based on visual inspection from the bridge using the ship's radar. The numbers did not change during the experiment to avoid confusion even if no measurements were performed on Sites 1 -4. At Sites 5-9 (Fig. 2a) the different disciplines conducted time-series studies of meteorological, sea-ice physical, biological, biogeochemical, and oceanographic parameters (Tab. 1). The under-ice environment was sampled by means of sediment traps, divers, and a small ROV. To both sides of the floe trajectory helicopters with an operational range of $120 \mathrm{~km}$ conducted sea-ice thickness and ice dynamic measurements, iceberg marking, and water column sampling. For the latter, a newly developed portable winch with $2000 \mathrm{~m}$ cable to allow for online data transmission was used. On 2 December, 2004 the floe cracked into several pieces, reducing the main station floe to a size of $1.5 \mathrm{~km} \times 1.5 \mathrm{~km}$ (Fig. 2a \& b). This caused a further differentiation of the sampling sites (Fig. 2a) into sampling locations (1-19, (Fig. 2b)), all listed in (Tab. 2). On 24 December the ice floe again fractured, leaving a piece of $0.7 \mathrm{~km} \times 0.8 \mathrm{~km}$ for the rest of the experiment. The day after, RV Polarstern moved to the edge of Site 9 and most activities were 
re-located to allow for easier access to the instruments, a more efficient field work, and better data comparison. Despite these interuptions, all teams were able to successfully complete their investigations till the end of the drift on 2 January, 2005. The chronology of major events of the ISPOL experiment is summarized in Table 3 and a detailed cruise diary with meta-data information can be found at http://web.awi.de/php/ISPOL/main.php.

\section{The collection}

The following collection comprises 15 contributions covering the results of all disciplines which participated in ISPOL. One considers the meteorological aspect of weather conditions in the context of long-term climate variability. A sequence of four papers covers different aspects of sea ice ranging from ice dynamics and resulting deformations on various scales, changes in snow and ice thicknesses, to the physical parameters of ice of different age at the transition to austral summer. A series of six papers addresses the biology within the ice, at its base, and in the surrounding ocean, thus ranging from plankton to mammals. The four papers on the liquid phase of water consider the biogeochemical and physical processes in the ocean with the latter including the turbulent fluxes of momentum and heat at the ocean-ice interface, and the mixing and spreading of newly formed water masses in the study area. It has to be mentioned that the definition of the season, e.g. late spring or early summer, used by each discipline differs depending on the studied parameters.

We are certain that this collection will significantly contribute to our understanding of the physical processes fostering growth and decay of the perennial 
sea-ice cover in the western Weddell Sea. In addition, this knowledge will influence the design of the sea-ice component in future climate models. The results also show that the ice, despite its compactness, is home for high amounts of algal standing stocks therefore playing a significant role in the carbon dynamics of ice covered oceans, and providing the food for the overwintering krill prior to ice decay. Finally, this pack covers an ocean in which deep and bottom water is formed, but with a higher spatial and temporal variability than previously assumed, narrowing the Southern Ocean's ability to sequester greenhouse gases. The two previous major experiments, ISW-1 and ISPOL, studied the complex air-ice-ocean interaction and its influence on biology in different seasons. Both demand further interdisciplinary investigations covering the whole annual cycle east of the Antarctic Peninsula where the strongest changes in the Weddell Sea are to be expected. Due to severe logistical constraints such experiments require long-term planning and international cooperation.

\section{Acknowledgements}

We thank captain and crew of RV Polarstern and the members of the Logistic Department at Alfred Wegener Institute for Polar and Marine Research (AWI) for their continuous support, essential for the success of a field experiment in a remote region of our globe. Special thanks to the European Space Agency (ESA) and the Danish Technical University (DTU) for free provision of nearreal-time satellite data. Assistance with figures by M. Nicolaus und J.M. Absy was most appreciated. 


\section{References}

[12] Andreas, E.L., Claffy, K.J., 1995. Air-sea drag coefficients in the western Weddell Sea: 1. Values deduced from profile measurements. Journal of Geophysical Research 100(C3), 4821-4831.

[12] Dieckmann, G.S., Haas, C., Schröder, M., Spindler, M., 2007. Ice Station POLarstern (ISPOL), in: El Naggar, Dieckmann, Haas, Schröder, Spindler (eds.), The expeditions ANTARKTIS-XXII/1 and XXII/2 of the research vessel "Polarstern" in 2004/2005. Reports on Polar and Marine Research $551,259 \mathrm{pp}$.

[12] Fritsen, C.H., Lytle, V.I., Ackley, S.F., Sullivan, C.W., 1994. Autumn bloom of Antarctic pack-ice algae. Science 266, 782-784.

[12] Gordon, A.L., 1993. Ice Station Weddell Group of Principle Investigators, and Chief Scientists, Weddell Sea exploration from ice station. Eos Transactions AGU 74(11), 121.

[12] Gordon, A.L., 1998. Western Weddell Sea thermohaline stratification. In: Jacobs, S.S., Weiss, R.F. (Eds.), Ocean, Ice, and Atmosphere. Antarctic Research Series 75, AGU, Washington DC, pp. 215-240.

[12] Haas, C., 2001. The seasonal cycle of ERS scatterometer signatures over perennial Antarctic sea ice and associated surface ice properties and processes. Annals of Glaciology 33, 69-73.

[12] Haas, C., Thomas, D.N., Bareiss, J., 2001. Surface properties and processes of perennial Antarctic sea ice in summer. Journal of Glaciology 47(159), 613-625.

[12] Lytle, V.I., Ackley, S.F., 1996. Heat flux through sea ice in the western Weddell Sea. Journal of Geophysical Research 101, 8853-8868.

[12] Naveira Garabato, A.C., McDonagh, E.L., Stevens, D.P., Heywood, K.J., 
Sanders, R.J., 2002. On the export of Antarctic Bottom Water from the Weddell Sea. Deep-Sea Research II 49(21), 4715-4742.

[12] Schodlok, M.P., Hellmer, H.H., Rohardt, G., Fahrbach, E., 2006. Weddell sea-iceberg drift: 5 years of observations, Journal of Geophysical Research 111(C6), doi:10.1029/2004JC002661.

[12] Schröder, M., Hellmer, H.H., Absy, J.M., 2002. On the near-bottom variability in the north- western Weddell Sea. Deep-Sea Research II 49(21), 4767-4790.

[12] Thomas, D.N., Engbrodt, R., Giannelli, V., Kattner, G., Kennedy, H., Haas, C., Dieckmann, G.S., 2001. Dissolved organic matter in Antarctic sea ice. Annals of Glaciology 33, 297-303. 


\section{Captions}

Fig. 1. Cruise tracks of Ice Station POLarstern (ISPOL - orange/red; austral spring 2004/05), and Ice Station Weddell (ISW - dark green; austral fall 1992). The ISPOL track is devided in transit across central Weddell Sea (orange) and drift along the western continental slope (red). (a) Overview of the western Weddell Sea including the ice edge positions from 15 November, 2004 (one day after entry to the pack) and 3 January, 2005 (day of leaving the pack) derived from SSMI/I data. Depth contour interval is 1000 m. (b) Enlarged drift tracks of ISPOL and ISW in the ISPOL study area. Dates mark special ISPOL events listed in Table 1. The range of helicopter activities to both sides of the ISPOL track corresponds approximately to the size of the depicted domain. Depth contour interval is $250 \mathrm{~m}$.

Fig. 2. ISPOL floe after initial break-up on 2 December, 2004 and prior to the second decay on 24 December, 2004. (a) Aerial photo of the ISPOL floe on 22 December, 2004 together with RV Polarstern (courtesy I. Arndt). Sampling sites are labeled as used in this issue and described in Tab. 1. Site 5 is located outside to the right. (b) Same as (a) but sketched for the distribution of sampling locations (explained in Tab. 2) after a further differentiation of the sampling sites 7-9. Solid and dashed lines represent the ice floe edges on 22 December and 25 December, after RV Polarstern had moved to the edge of Site 9, respectively. Also marked are three main haul roads for snow-scooter traffic (gray dashed lines) and the location of the rescue hut (grey dot) (courtesy M.McPhee). (c) Ice thickness distribution on various days during the ISPOL drift (courtesy C. Haas). 
Table 1

List of sampling sites (1-9) on the ISPOL floe for time-series studies of meteorological, sea ice physical, biological, biogeochemical, and oceanographic parameters.

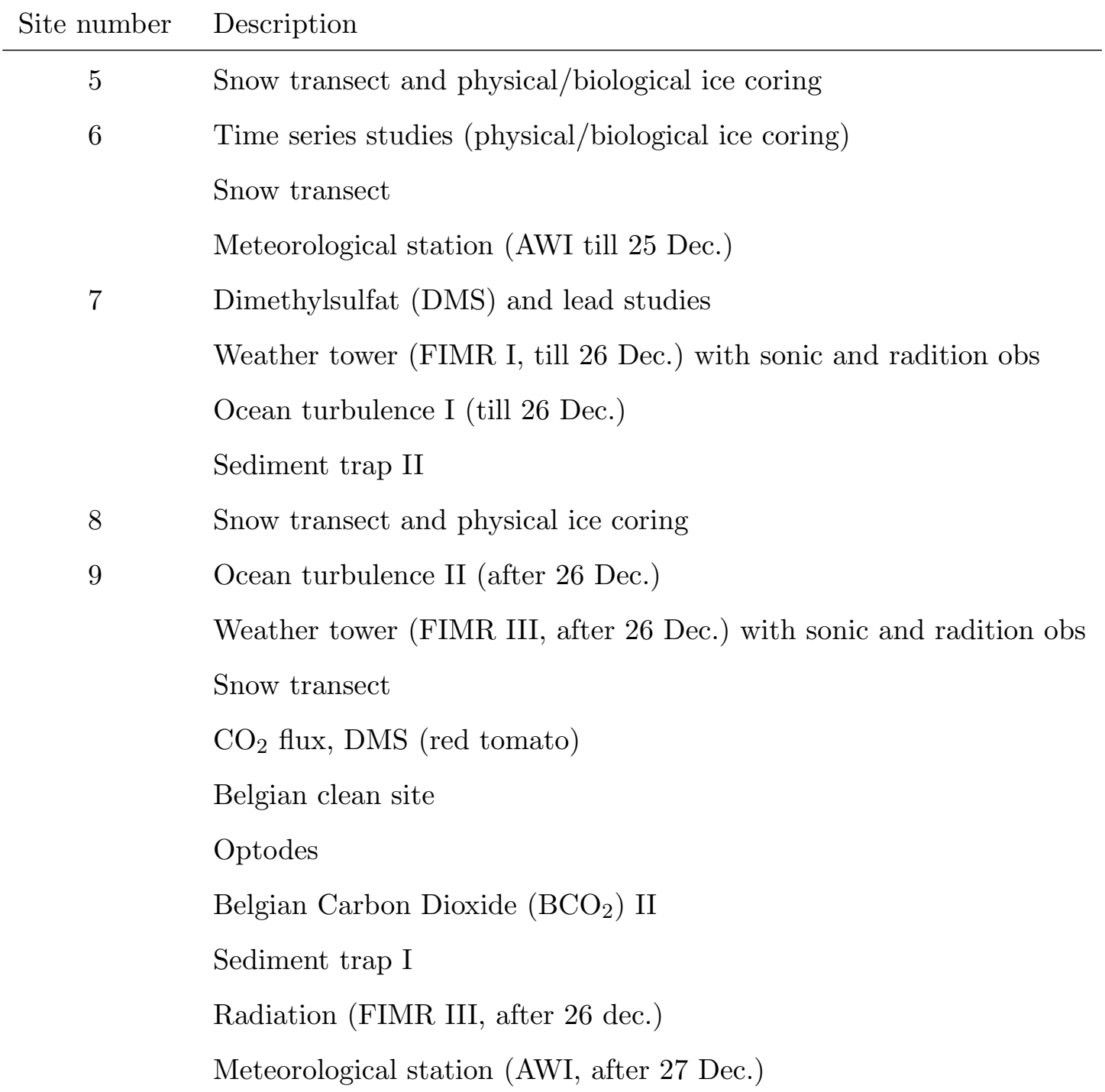


Table 2

List of sampling locations on the ISPOL floe after first break-up on 2 December, 2004 (Fig. 2b), description of measurements, and sampling sites (Fig. 2a) as origin of the new sampling locations. Time-series measurements still continued at sites $5 \& 6$, though detached from the main floe.

\begin{tabular}{clc} 
Location & Description & Site \\
\hline 1 & Dimethylsulfat (DMS) sampling & 7 \\
2 & Meteorological mast, radiometer & 7 \\
3 & Meteorological mast & 7 \\
4 & Meteorological station (AWI till 25 Dec.) & 7 \\
5 & Ocean turbulence I (till 26 Dec.) & 7 \\
6 & Sediment trap II & 7 \\
7 & Davids tent & 7 \\
8 & Snow trench & 8 \\
9 & Ocean turbulence II (after 26 Dec.) & 9 \\
10 & Meteorological tower (FIMR III, after 26 Dec.) & 9 \\
11 & Snow depth line & 9 \\
12 & Radiometer I & 9 \\
13 & Atmospheric turbulence II & 9 \\
14 & Flux mast, tomato I & 9 \\
15 & Clean site & 9 \\
16 & Optodes & 9 \\
17 & Belgian Carbon Dioxide (BCO 2$)$ & 9 \\
18 & Sediment trap I & 9 \\
19 & Meteorological station (AWI, after 27 Dec.) & 9 \\
& & 9
\end{tabular}


Table 3

Chronology of major events of the ISPOL experiment.

Site number Description

06 Nov. 2004 Departure from Cape Town.

14 Nov. 2004 First ice station during Weddell Sea transect.

27 Nov. 2004 Arrival at ISPOL floe and last transect station.

28 Nov. 2004 Start of drift station with Polarstern anchored at Site 7.

29 Nov. 2004 First day of ice station field work (floe size $\sim 10 \times 10 \mathrm{~km}$ ).

02 Dec. 2004 First floe break-up, reduction to $\sim 1.5 \times 1.5 \mathrm{~km}$.

Separation of Sites 5 and 6.

13 Dec. 2004 Change of drift pattern, stropplementng E-W components.

24 Dec. 2004 Second floe break-up, reduction to $\sim 0.7 \times 0.8 \mathrm{~km}$.

Separation of Sites 7 and 8.

25 Dec. 2004 Re-location of Polarstern to the edge of Site 9.

28 Dec. 2004 Change of drift pattern, strong northward component.

02 Jan. 2005 End of drift station after 36 days.

03 Jan. 2005 Last ice station in the marginal ice zone.

19 Jan. 2005 Arrival in Cape Town and end of the ISPOL experiment. 

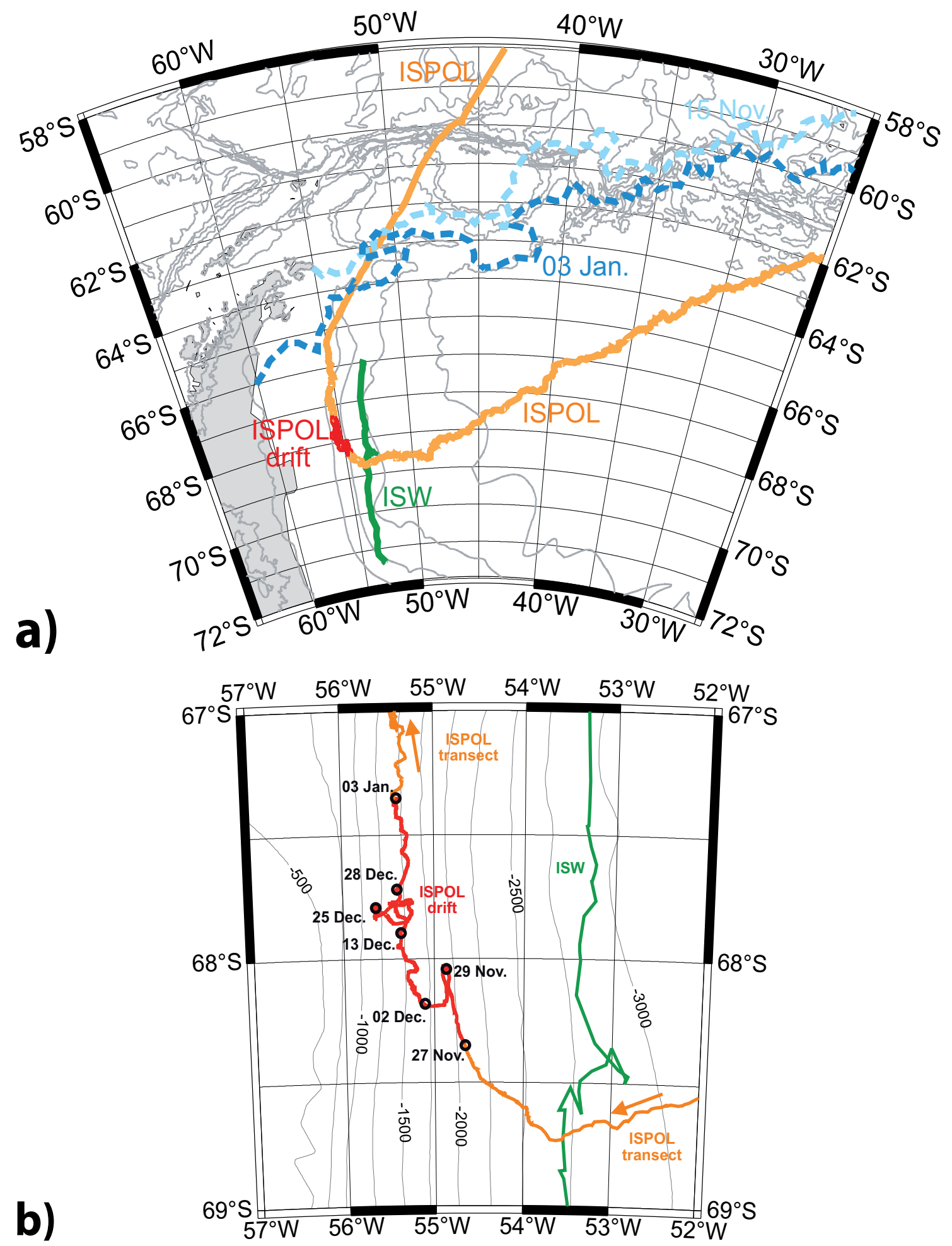

Fig. 1. 

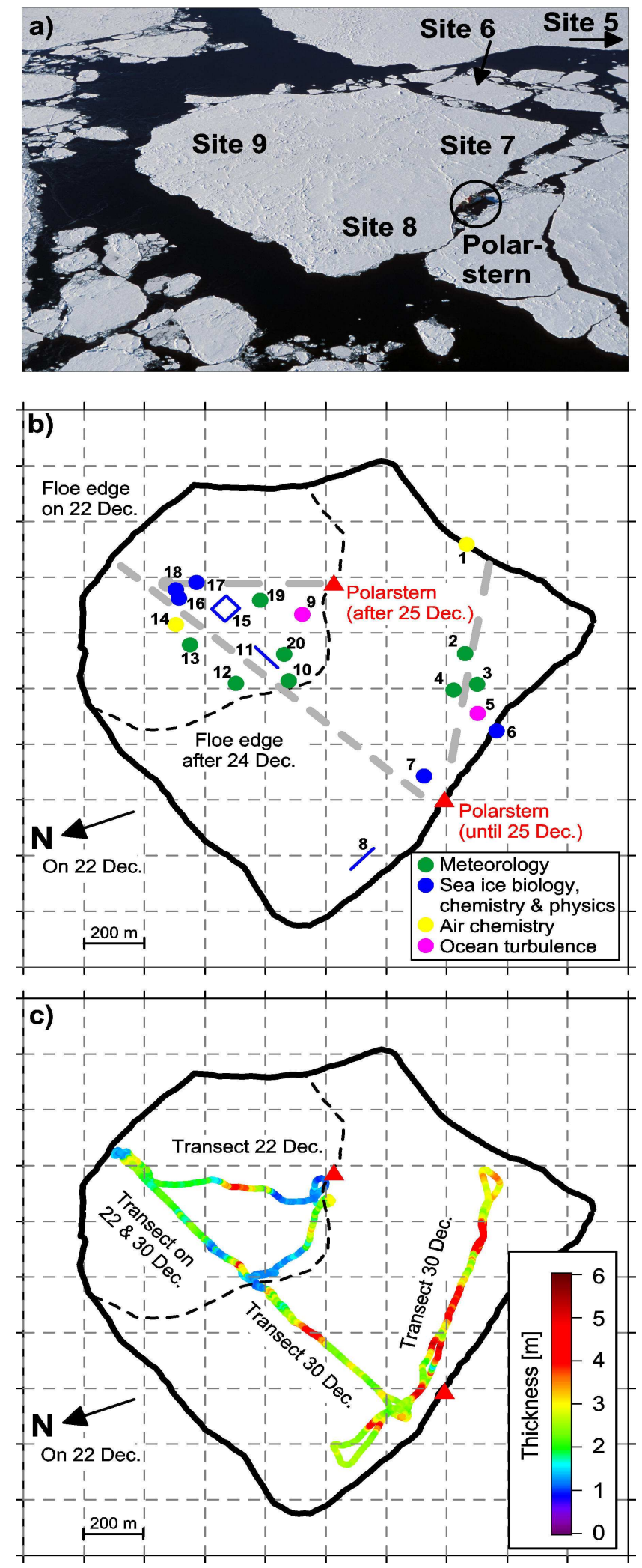

Fig. 2. 